\title{
História e diálogo entre culturas: contributos da teoria de Jörn Rüsen para a orientação temporal dos jovens
}

\author{
Isabel Barca \\ Profa. Associada do CIEd - Universidade do Minho \\ isabar@ie.uminho.pt
}

Recebido em 09/04/2017. Aprovado em 18/09/2017.

Como citar este artigo: Barca, Isabel. "História e diálogo entre culturas: contributos da teoria de Jörn Rüsen para a orientação temporal dos jovens”. Intelligere, Revista de História Intelectual, vol. 3, nº2, p. 77-89. 2017. Disponível em http://revistas.usp.br/revistaintelligere $>$. Acesso em dd/mm/aaaa.

Resumo: O artigo discute os contributos da teoria da consciência histórica de Rüsen na pesquisa em educação histórica desenvolvida em Portugal. Analisa convergências epistemológicas entre essas duas abordagens e destaca a relevância da ideia de consciência histórica, discutida por Rüsen, no processo de aprender a pensar historicamente. Neste sentido, apresenta exemplos de pesquisa empírica sobre narrativas de jovens portugueses em História e reflete sobre possibilidades investigativas e didáticas tendo em mente a construção do pensamento histórico dos jovens e a sua orientação temporal.

Palavras-chave: Rüsen e Educação histórica; narrativas de jovens; consciência histórica de jovens portugueses.

\section{History and dialogue between cultures: contributions of Jörn Rüsen's theory for the temporal orientation of young peple}

\begin{abstract}
The paper discusses the main contributions of Rüsen's historical consciouseness theory to history education research carried out in Portugal. It analyses epistemological convergences between the two approaches enhancing the relevance of Rüsens's idea of historical consciousness to the process of learning to think historically. It gives some examples of empirical research on historical accounts of Portuguese youth followed by a reflection about investigative and didactic possibilities oriented to constructing the historical thinking of young people and their temporal orientation.
\end{abstract}

Keywords: Rüsen and history education; Historical narratives of young people; Historical consciousness of Portuguese youth. 


\section{Introdução: investigação em educação histórica}

A discussão desenvolvida por Jörn Rüsen em torno da consciência histórica veio realçar e aprofundar o sentido humano da abordagem de investigação ligada a aprender a pensar historicamente. Nos seus inícios na década de 1970 em Inglaterra, esta linha de pesquisa em Educação histórica procurou - e com êxitos consideráveis - responder à questão da importância de incluir a História no elenco curricular. Eram tempos de discussões efervescentes na Educação ocidental: a preocupação com a relevância social de preparar para a vida levava à proposta de dar a conhecer às crianças e jovens o mundo em redor (pelos Estudos Socais), em detrimento do estudo do passado que, segundo os defensores de tal proposta, de pouco serviria para entender o presente. Adicionalmente, a popularidade da teoria piagetiana de desenvolvimento cognitivo das crianças por níveis etários veio acrescentar argumentos para a redução da História no currículo uma vez que esta disciplina trata de questões longínquas no tempo, supostamente muito abstractas na perspectiva piagetiana e que, por isso, não seriam entendidas antes da adolescência. Perante tais convicções em desvalorizar a História como disciplina útil na Educação formal, um grupo de historiadores e filósofos da História, particularmente dos que se ligavam também à Educação, lançou o desafio de refutar tais argumentos através de uma sólida argumentação epistemológica. Nessa linha, encetaram-se estudos em cognição histórica para indagar as possibilidades de alunos construírem ideias históricas mesmo sem terem atingido o estádio de operações lógico-dedutivas, contra o que a teoria piagetiana de desenvolvimento cognitivo defendia. Através de corroboração empírica, as pesquisas sugeriram - e continuam a sugerir agora mais claramente numa era de maior informação - que crianças e jovens podem aprender História quando ela é apresentada com sentido humano. ${ }^{1}$

Um rol de eventos ou até mesmo de explicações únicas do passado não chega para dar sentido humano ao passado e a partir dele estabelecer conexões abertas com o presente, pois pensar historicamente envolve muito mais. Ninguém pode escapar ao passado, por isso existe no ser humano uma necessidade intrínseca de conhecer as raízes deste presente, tal como Peter Lee e Raymond Martin, entre muitos outros, realçaram. ${ }^{2}{ }^{3}$ Conhecer as próprias raízes para melhor se entender a si próprio no mundo implica conhecer, de forma vicariante, outros seres humanos do presente e do passado, as suas formas de pensar, intenções e decisões, seja em diálogo, em tensão, ou mesmo em conflito. Como diz Lowental, ${ }^{4}$ o passado é um país estranho e essa estranheza, em simultâneo com a perplexidade e curiosidade que eventualmente provoca, pode contribuir para a descoberta de uma história humana mais inteligível na sua complexidade, nas suas contradições, nos seus interesses de grupos específicos, mas também feito de utopias sobre a felicidade e o bem comum pelas quais se luta e até se morre.

Pensar historicamente significa não só compreender 'conteúdos' sobre o passado humano, mas também e, necessariamente, perceber de que forma essa compreensão se 'fabrica' através da interpretação de fontes variadas. Com estes princípios epistemológicos, a investigação em Educação histórica enveredou pela busca de sentidos sobre como alunos - e docentes e outros sujeitos intervenientes na educação formal e informal - vão aprendendo a aproximar-se de uma compreensão histórica genuína - analisar fontes à maneira (próxima) do historiador, comparando mensagens convergentes e contraditórias para chegar a 'conclusões' sobre o passado fundamentadas na evidência. Tais conclusões serão mais abrangentes e equilibradas se derivarem da interpretação, cruzamento e avaliação de várias fontes - que abrangem não só a testemunhos e posições dos sujeitos que viveram uma dada situação, mas

$1 \mathrm{O}$ sentido humano das situações facilita a aprendizagem das crianças, como defendia

Margaret Donaldson, Childrens's mind (Londres: Fontana, 1978).

2 Peter Lee, "Why Learn History?". In: Learning History, eds. Alaric Dickinson, Peter Lee e Peter Rogers (London, Heinemann Educational Books, 1984).

${ }^{3}$ Raymond Martin, The Past Within Us (Princeton: Princeton University Press, 1989).

${ }^{4}$ David Lowental, The Past is a Foreighn Country (Cambridge: Cambridge University Press, 1985). 
também (as) versões posteriores sobre a mesma. Assim como na sociedade não existe um pensamento único e homogéneo também na narrativa histórica não haverá uma explicação fechada ou uma única forma de olhar o passado. Em História há lugar a várias interpretações do passado, que devem ser analisadas e avaliadas quanto à sua relativa consistência empírica e lógica.

Por isso, dá-se atenção às formas como os alunos constroem as suas ideias sobre o que, como e por que aconteceu um dado passado, por referência a noções de explicação, significância, multiperspectiva e evidência - conceitos que enformam a natureza da História. O desenvolvimento do pensamento histórico tendo em atenção estes ingredientes pode contribuir para a formação de jovens mais informados e analíticos e, nesse sentido, mais críticos.

\section{Pensamento histórico e consciência histórica dos jovens}

A conceptualização que se propunha para a educação dos jovens no último quartel do séc. XX em torno do pensamento histórico implica um sentido humanista que, contudo, poderia não ser compreensível à primeira leitura. Os fundamentos epistemológicos e as conclusões das pesquisas desenvolvidas nesta linha pareciam, a um olhar menos profundo, demasiado 'cerebral', despojadas de emoção. Faltava, pois, uma ideia nuclear que sintetizasse de forma mais explícita estas potencialidades para a Educação histórica; a ideia de consciência histórica na perspectiva de Jörn Rüsen veio preencher essa lacuna. Essa ideia veio iluminar com maior clareza o sentido humano da História na formação dos jovens.

Em Portugal, o diálogo da investigação em Educação histórica com a teoria da consciência histórica desenvolvida por Rüsen aconteceu nos finais do séc. XX, através do artigo "The development of narrative competence in historical learning: an ontogenetic bypothesis concerning moral consciousness" ${ }^{5}$ Este primeiro encontro com a linha conceptual de Rüsen permitiu-nos não só discutir a ideia de consciência histórica na sua relação com a Educação histórica como também encetar uma fecunda 'linha' de trabalhos investigativos com base nos princípios nucleares de orientação temporal, matriz disciplinar da História e tipos de consciência histórica. Em Portugal, esta pesquisa tem sido realizada sobretudo no âmbito do projeto "Consciência Histórica - Teoria e práticas (Hicon I e II) e das suas extensões até ao presente. ${ }^{6}$ Para encontrar respostas fundamentadas à questão "que consciência histórica revelam os jovens em situação de escolaridade?” - e também sobre consciência histórica de professores - buscaramse, nas várias tarefas investigativas do Projeto Hicon, recolha e análise de dados que permitissem a compreensão de noções epistemológicas interligadas com uma concepção abrangente da natureza do conhecimento histórico (numa perspectiva ocidentalizada). Essas noções epistemológicas passam designadamente pela evidência (com base em fontes de vários tipos e pontos de vista), significância, explicação, empatia (sendo esta relacionada com abordagens de 'inter-identidades' sociais), narrativa - que constituem elementos essenciais do conhecimento histórico e que contribuem para moldar sentidos tácitos ou explícitos de orientação temporal.7_8_9_10_11_12 O método utilizado, de natureza essencialmente qualitativa,

\footnotetext{
${ }^{5}$ Jörn Rüsen, “The development of narrative competence in historical learning: an ontogenetic hypothesis concerning moral consciousness". In: Studies in metahistory, ed. P. Duvenage (Pretoria, Human Sciences Research Council, 1993). Esta primeira aproximação à teoria de Jörn Rüsen foi-nos proporcionada por Peter Lee, no âmbito de encontros sistemáticos de investigação em educação histórica.

${ }^{6}$ Projecto Consciência Histórica -Teoria e Práticas (I e II) (financiado pela Fundação para a Ciência e Tecnologia (FCT), Portugal, 2003-2011).

7 Isabel Barca e Olga Magalhães, "O Passado e o Presente: um estudo no âmbito do Projecto Consciência Histórica Teoria e Práticas", O Estudo da História, [vol.] 5 (2004) (66-75).

${ }^{8}$ Marília Gago, "Concepções de Professores sobre narrativa histórica" (Tese de doutorado, Universidade do Minho, 2007).

9 Maria Auxiliadora Schmidt, "Perspectivas da consciência histórica e da aprendizagem em narrativas de jovens brasileiros", Revista Tempos Históricos, [vol.] 12, 1 (2008) (81-96).
} 
serviu propósitos de análise em profundidade, privilegiando uma abordagem indutiva inspirada na Grounded Theory. ${ }^{13}$ Em consequência, os participantes nesses estudos são selecionados atendendo-se a critérios de estratificação por 'variáveis' consideradas relevantes (ano de escolaridade, sucesso escolar e contexto cultural no caso dos alunos; formação e experiência profissional no caso dos professores). Inspirados pela ideia nuclear de que a 'narrativa é a face da consciência histórica' os estudos do Projeto Hicon rapidamente evoluíram para um enfoque especial na exploração das narrativas históricas fornecidas por alunos. Estes estudos têm vindo a corroborar as potencialidades de, pelas narrativas, se aceder à compreensão das formas de cultura e de consciência histórica dos sujeitos inquiridos.

O contacto da comunidade investigativa de educação histórica em Portugal com a obra de Rüsen em língua portuguesa aconteceu no Brasil em meados da primeira década do séc. XXI, graças à tradução e acompanhamento esclarecido que nos tem sido proporcionado pelo filosofo Estêvão Rezende Martins ${ }^{14}{ }^{15}{ }^{16}$. Esta situação abriu amplas possibilidades ao conhecimento da obra de Rüsen no seio da comunidade lusófona que investiga em Educação histórica, e tem suscitado uma adesão entusiástica aos seus princípios para dar mais sentido humano às pesquisas sobre ideias dos jovens em História ${ }^{17}$. Em paralelo com a expansão da pesquisa em Educação histórica no Brasil e em Portugal sob inspiração da teoria de Rüsen, a exploração de narrativas de jovens sob diversos enfoques - passando sempre pela atenção às ideias discutidas por Rüsen - estendeu-se a países de expressão portuguesa como Cabo Verde, ${ }^{18}$ Moçambique $^{19}$ e Angola ${ }^{20}$.

\section{Avanços na educação para a consciência histórica}

Como Rüsen tem debatido, ${ }^{21}{ }_{-22} 23$ a base para a compreensão da vida no passado - e, portanto, do saber histórico - é a experiência do quotidiano que compele o sujeito a buscar no passado elementos significativos que sejam úteis para as suas decisões no presente, com vista naturalmente a um melhor futuro. O saber histórico deriva desta necessidade, e com as suas teorias, conceitos e métodos vai influenciar, por sua vez, a orientação temporal dos seres humanos no seu quotidiano.

${ }^{10}$ Júlia Castro, "Diálogo e conflito - pensamento histórico e ideias de interculturalidade de jovens portugueses. In: Aprender História: Perspectivas da Educação Histórica, orgs. M. Auxiliadora Schmidt e Isabel Barca (Ijuí: Unijuí, 2009).

${ }^{11}$ Isabel Barca, "Identities and History: Portuguese students' accounts", International Journal

of Historical Learning, Teaching and Research, [vol.] 8,1 (2009) (19-27).

12 Isabel Barca e Maria Auxiliadora Schmidt, "La consciencia histórica de los jóvenes brasileños y portugueses y su relación con la creación de identidades nacionales", Educatio siglo XXI, [vol.] 31, 1 (2013) (25-45).

13 Anselm Strauss e Juliet Corbin, Basics of qualitative research. Grounded Theory. Procedures and techniques (Newbury Park: Sage, 1991).

$14 \mathrm{O}$ contacto com as obras de Rüsen em português e com o seu tradutor, Estêvão Rezende Martins, foi-nos proporcionado pela pesquisadora Maria Auxiliadora Schmidt, fundadora e coordenadora do LAPEDUH - Laboratório de Pesquisa em Educação Histórica, sediado na Universidade Federal do Paraná (UFPR).

${ }^{15}$ Maria Auxiliadora Schmidt, Isabel Barca e Estêvão Rezende Martins, Jörn Rüsen e o ensino

de História (Curitiba-PR: Editora UFPR, 2010).

${ }^{16}$ Estêvão Rezende Martins, "Humanismo: a utopia necessária e sua historicidade". In: Jörn Rüsen e o ensino de História", orgs. Maria Auxiliadora Schmidt, Isabel Barca e Estêvão Rezende Martins (Curitiba PR: Editora UFPR, 2010).

17 Maria Auxiliadora Schmidt e Lucas Pydd Nechi, Brazilian Investigation in bistory education

(Curitiba: W. A. Editores, 2016).

${ }^{18}$ Graça Sanches, "Ideias dos alunos acerca da significância da História Contemporânea: un estudo com alunos do ensino secundário em Cabo Verde” (Dissertação de Mestrado, Universidade do Minho, 2008).

${ }^{19}$ Isabel Barca, "History and temporal orientation: The views of Portuguese-speaking students". In: Joined-up history: New Directions in History Education Research, eds. Arthur Chapman e Arie Wilschut (Charlotte, NC: Information Age, 2015).

${ }_{20}$ Angelina Aguiares, "Construir conbecimento histórico em contexto angolano: um estudo em torno de uma experiência de aula oficina"

(Tese de doutorado, Universidade do Minho, 2017).

${ }^{21}$ Jörn Rüsen, 1993 (ibid.).

22 Jörn Rüsen, Razão Histórica. Teoria da História: os fundamentos da ciência histórica (Brasília: UniB, 2001).

${ }^{23}$ Jörn Rüsen, "Historical Consciousness: Narrative Structure, Moral Function and Ontogenetic Development". In Theorizing Historical Consciousness, ed. Peter Seixas (Toronto: University of Toronto Press, 2004). 
Na matriz Ruseniana, o movimento da formação da consciência histórica que tem origem nas necessidades de orientação temporal dos sujeitos traduz-se num primeiro sinal de pulsão humana para entender a sua vida pelo conhecimento de muitas outras vidas. Claro que este conhecimento pode ser feito apenas ao nível do senso comum, por observação direta, pelas estórias familiares e do meio envolvente, pelos vestígios materiais do passado e pelos relatos da mídia tantas vezes fragmentados ou romanceados; mas a estreiteza ou a fragmentação destas experiências de senso comum e a forma impressionista como a informação é processada pelo sujeito pode fornecer alguma sabedoria (os ditados populares são disso exemplo) mas também pode ser fonte de preconceitos e de concepções fantasiosas sobre o mundo. As experiências quotidianas ganham relevo na orientação temporal - como em todas as outras formas de orientação no mundo - quando impulsionam o sujeito a conhecer a vida de forma mais sistemática, profunda e (talvez?) mais segura. Há que ter em conta que as ideias alternativas à ciência com base nas experiências quotidianas podem trazer obstáculos a uma atitude aberta ao avanço do saber. É por estas vertentes contraditórias do conhecimento com base apenas na vida quotidiana que em Educação se considera essencial a exploração das ideias prévias dos alunos. Como diz Peter Lee, ${ }^{24}$ só se pode mudar (conscientemente) aquilo que se conhece; a indagação das ideias prévias, tácitas ou claramente assumidas, é essencial para ajudar os alunos numa construção conceptual que vá além do senso comum que, no plano do conhecimento social, resulta por vezes no apego a mitos, lendas, estereótipos ou dogmas. Algumas destas posturas sem confirmação científica poderão até manter-se contanto que não obstem ao desenvolvimento de atitudes mais avançadas (o ser humano é contraditório). Mas no quotidiano da educação histórica formal são férteis os exemplos de mal entendidos em torno de conceitos substantivos; as ideias alternativas ao saber histórico, outrora consideradas simplesmente anedóticas, devem ser conhecidas e exploradas pelos formadores, com respeito por quem as expressa e com tacto profissional para ajudar à mudança conceptual. Algumas dessas ideias alternativas são persistentes e frequentes mesmo até em adultos com alguma formação histórica: por exemplo em Portugal, um país de regime republicano e com uma maioria de formação católica, não é raro observar uma identificação de monarquia com ditadura, ou de catolicismo com cristianismo.

Já no plano das concepções estruturais do saber histórico, a investigação na área específica tem mostrado que existe uma progressão na construção da forma de pensar historicamente (embora com oscilações por vezes independentes da faixa etária) quando é favorecida pelo contexto educativo. Essa progressão pode avançar desde uma posição fixa de estranheza acerca de decisões e ações de seres humanos no passado (quando elas parecem ilógicas à luz do quotidiano experienciado pelos alunos), até um raciocínio próximo do ofício do historiador (quando ultrapassam essa estranheza inicial e buscam compreender os outros atribuindo um sentido inteligível às suas ações). Esta evolução conceptual acontece pelo cotejo de fontes diversificadas sobre um dado passado em estudo, procurando conhecer os contextos culturais respetivos e colocando hipóteses quanto às motivações, razões e constrangimentos dos agentes históricos dessa situação.

Em suma, na ação investigativa e educativa de entender a construção do pensamento histórico dos alunos enriquecida pela teoria Ruseniana, percebe-se a valorização dos interesses e necessidades das crianças e dos jovens, que são os principais sujeitos intervenientes na sua própria aprendizagem. A “didática da História”, no sentido de práticas de ensino da História, poderá alimentar-se das propostas e de algumas conclusões da investigação nesse campo para melhor desempenhar o seu papel na formação de um pensamento histórico mais avançado. Para que esse papel seja mais frutuoso, é essencial que o profissional de ensino de História tenha ele próprio uma formação que abarque uma reflexão epistemológica sobre a sua

${ }^{24}$ Peter Lee, "Putting principles into practice: understanding history". In: How Students Learn, eds. Susanne Donovan e John Bransford (Washington, DC: The National Academies Press, 2005). 
disciplina de referência e, em coerência, o desenvolvimento de competências de exploração e acompanhamento da construção do pensamento histórico dos alunos. Este perfil profissional corresponde à proposta de "professor investigador", por oposição à de professor meramente técnico. ${ }^{25}$ Também nesta proposta, de cariz didático, os interesses e necessidades quotidianas dos sujeitos - profissionais de ensino - ganham visibilidade e atenção.

Por conseguinte, segundo esta abordagem a ação didática em História converge com a teorização da consciência histórica na perspectiva de Rüsen, quando coloca na História os sujeitos do nosso tempo, incluindo os professores, as crianças e os jovens das nossas escolas E, ao fazê-lo, diz-se implicitamente que também eles são agentes de uma história não prédeterminada. Ao dar-se vOz a quem aprende e ensina - que poderá exemplificar uma forma Ruseniana de atender aos interesses dos sujeitos - o sentido humanista de educar historicamente sai reforçado.

Será de realçar também que as potencialidades desta corrente vão muito mais além do que a valorização do sujeito singular: é no diálogo com os outros - do passado e do presente que se conhecem e comparam as diferenças de ponto de vista, se respeita a diversidade e se avalia a justeza de intenções e a ligação com a realidade das várias posturas. ${ }^{26}$ Há que ter em conta que, no leque dos interesses individuais, existem aqueles que são pautados por necessidades individuais ou de grupo estranhas ou até mesmo opostas a preocupações de sentido humanista. Há o ego e o etnocentrismo, há o dogmatismo, há a propaganda, há a ganância, tudo isto e muito mais que constituem a condição humana. O saber histórico, ao procurar entender e explicar as decisões e ações dos seres humanos em interação no passado em consenso e em divergência, em busca de convergências ou de ataque para dominar fornece pistas racionalmente fundamentadas para que os jovens ganhem disposições de respeito pelo outro, aprendam a comparar situações diversas e a argumentar racionalmente.

\section{Narrativas de jovens e consciência histórica}

É pela narrativa, sobretudo, que se comunica a compreensão histórica - por isso, como diz Rüsen, a narrativa é a face material da consciência histórica. Nela é possível perceber como o seu autor concebe o passado e permite compreender como ele estabelece relações do passado com o presente e o futuro. As visões sobre realizações e interações humanas nas suas várias dimensões, os sentidos de mudança, as mensagens nucleares sobre uma dada sociedade encontram-se aí plasmadas, de forma mais ou menos explícita. Por isso as relações entre narrativa histórica e consciência histórica dos jovens têm sido exploradas nas pesquisas em Portugal, estabelecendo-se um diálogo entre a reflexão epistemológica com base sobretudo nos trabalhos de Rüsen ${ }^{27}{ }^{28}$ ) e Wertsch ${ }^{29}$ e a 'escola britânica' de pesquisa em educação histórica. ${ }^{30}$ 31_32_33_.34 Assume-se, assim, que conhecer as narrativas históricas que os jovens vão

${ }^{25}$ Isabel Barca, “A aula oficina em História: do projecto à avaliação”. In: Para uma Educação Histórica de qualidade, org. Isabel Barca (Braga: CIEd, Universidade do Minho, 2004).

${ }^{26}$ Jörn Rüsen, "Humanismo intercultural: ideia e realidade". In: Humanismo e Didática da História: Jörn Rüsen (Curitiba PR: W.A. editores, 2015).

${ }^{27}$ Jörn Rüsen, 2004 (ibid.).

${ }^{28}$ Jörn Rüsen, Time \& History. The variety of cultures (Oxford: Berghahn Books, 2007).

${ }^{29}$ James Wertsch, Voices of Collective Remembering (Cambridge: Cambridge University Press, 2002).

${ }^{30}$ Peter Lee, "Walking backwards into tomorrow": Historical consciousness and understanding history" (Centre for the Study of Historical Consciousness, University of British Columbia, Vancouver, www.cshc.ubc.ca).

31 Peter Lee, 2005 (ibid.)

32 Denis Shemilt, "The Caliph's Coin: The currency of Narrative Frameworks in History Teaching”. In: Knowing Teacbing \& Learning History: National and International Perspectives, eds. Peter Stearns, Peter Seixas e Samuel Wineburg (New York: New York University Press, 2000).

${ }_{33}$ Rosalyn Ashby, Peter Lee e Denis Shemilt, "Putting Principles into Practice: Teaching and Planning". In: How students learn: history in the classroom, eds. M. S. Donavan e J. Bransford (Washington, DC: The National Academies Press, 2005).

${ }^{34}$ Arthur Chapman \& Arie Wilschut, Joined-up history: New Directions in History Education

Research (Charlotte, NC: Information Age, 2015). 
construindo ao longo da sua educação histórica (formal e informal) constitui uma atitude investigativa essencial para que se torne possível uma monitorização consciente das aprendizagens e da formação da consciência histórica.

Uma das incidências privilegiadas nos estudos do Projeto Hicon sobre narrativas dos jovens tem sido a de se propor aos alunos que narrem a História contemporânea a nível nacional e a nível global. Tais narrativas produzidas pelos jovens têm fornecido pistas interessantes sobre os sentidos e formas de construção de cultura e consciência histórica, nomeadamente quanto a elementos do passado considerados significativos e valorações positivas ou negativas sobre eles, teorias da história, questões de identidade e de orientação temporal. A análise de narrativas de jovens portugueses obtidas em várias etapas de recolha de dados (entre 2004 e 2016) tem vindo a revelar uma abordagem (tácita ou explícita) da História com caráter descritivo/explicativo embora reproduzindo, quase sempre, e apenas, algumas causas e consequências convencionais, no sentido de que são transpostas dos manuais escolares e/ou dos discursos dos professores. A ideia de uma História simplesmente cronológica ou descritiva é pouco comum assim como também o é (a um nível mais sofisticado se se tiver em conta os parâmetros epistemológicos da historiografia ocidental) a consideração de fatores que se possam considerar originais e consistentes com a evidência. Por outro lado, e tendo em conta as necessidades de construção de identidades coletivas, os resultados das pesquisas com jovens portugueses mostram uma mensagem nuclear recorrente de identificação positiva com o país e de um certo distanciamento e postura de crítica negativa em relação à história do mundo contemporâneo. A própria substanciação histórica revelou-se mais avançada na escrita sobre a História nacional do que sobre a História mundial.

Apresenta-se a seguir três exemplos de narrativa sobre a História contemporânea produzidas por jovens do $9^{\circ}$ ano de escolaridade, em 2011. A primeira, referente à escala nacional, foi considerada uma narrativa histórica coerente por incluir vários marcadores políticos, sociais e económicos em relação ao período demarcado; a segunda e a terceira, ambas referentes à escala 'global', configuram uma estrutura narrativa menos avançada: a primeira delas foi considerada uma narrativa emergente, pois debruça-se apenas sobre uma situação do passado (II Guerra Mundial); a última surge como um leque de comentários genéricos sobretudo em torno de tempos mais recentes.

Uma narrativa nacional coerente

Bem há cerca de 100 anos começou a república, com a queda da monarquia. Salazar governou o país numa ditadura que inspirou medo a todo o país. Torturava pessoas, e viviam num país não livre. Governou-o durante vários anos. Salazar teve um acidente e ficou incapacitado de governar o país, passando esse 'poder' a Marcelo Caetano, que governou segundo as bases de Salazar, mas tentou 'suavizar' um pouco as coisas. Portugal, farto da ditadura, organizou uma Revolução dos Cravos ou 25 de Abril. Ao longo dos anos, o país foi enfrentando vários problemas. Em 2001, foi criada a moeda atual da União Europeia, o Euro. Agora, em 2011, estamos a enfrentar uma enorme crise económica, que se alastra por Portugal. (Jorge, 15 anos)

Uma narrativa emergente sobre o mundo

Há cerca de 100 anos...Hum... Não sei muito bem, mas a ação de que me lembro passou-se na Alemanha, com a ditadura de Hitler. Hitler dominou vários países à volta da Alemanha, o que deu origem à $2^{\mathrm{a}}$ Guerra Mundial. Na $2^{\mathrm{a}}$ Guerra Mundial, os EUA e a sua aliança lutaram contra a Alemanha e o Japão. Após a libertação dos países, a 
Alemanha foi dominada, Hitler suicidou-se e o país foi livre do mal de Hitler. Entretanto o Japão recusava-se a render, o que levou a que os EUA largassem uma bomba atómica no Japão. (Marta, 15 anos)

Uma narrativa genérica sobre o mundo

De agora para cá, muito mudou, o mundo mudou, e a cada dia que passa custa viver cá. O aumento da poluição está a originar vários problemas que as gerações futuras vão enfrentar. Em 2001, houve um ataque terrorista às Torres Gémeas. A Grécia entrou em crise. Nestes dias, a sociedade está má. Completamente pegados às tecnologias, dependentes dos seus vícios, é cada vez mais perigoso andar na rua, as pessoas ganharam malícia, rancor... Sonho com o mundo sem guerra e sem violência. Mas digo bem, não passa de um sonho. (Luís, 15 anos)

Nas duas primeiras narrativas atrás apresentadas sobressai a dimensão política, com consequências socioeconómicas (e ambientais). Na terceira e última narrativa, formada por comentários genéricos, estão presentes dimensões ambientais, tecnológicas, económicas, político-militares, de segurança e de costumes ao nível quotidiano, num registo de senso comum baseado sobretudo em informações da mídia. Contudo, transversalmente aos três textos perpassam juízos de valor convergentes: liberdade, paz, segurança, sustentabilidade económica ou questões ecológicas são valores tendencialmente apreciados pelos jovens.

Em 2016 efetuou-se uma nova recolha de dados, desta vez com a solicitação de um relato sobre a História nacional, a alunos de $9^{\circ}$ ano a frequentar escolas de Lisboa e Porto. A análise dos dados sugere uma mensagem nuclear muito próxima da mensagem encontrada nos estudos anteriores no que se refere ao Portugal contemporâneo. Apesar disto, o sentido crítico dos jovens sujeitos parece manifestar-se agora de forma mais aberta e, por vezes, com uma busca de explicações para as dificuldades socioeconómicas no presente :

Depois das revoltas e várias guerras... vem a época de ouro dos portugueses altura em que os portugueses descobriram o Brasil, a costa de África.... Nesta altura entrou muito dinheiro mas os portugueses não aproveitaram essa riqueza para desenvolver o país, gastavam o dinheiro em luxos. Depois deram-se as primeiras duas guerras mundiais onde Portugal não teve grande importância, no tempo da II Guerra Portugal vivia-se numa ditadura com Salazar... e essa ditadura acabou no dia 25 de abril, uma revolução que nos libertou mas que também estragou a economia do país até aos dias de hoje... em crise com uma indústria pouco desenvolvida, pois importamos mais do que exportamos. (Alice, 15 anos)

Narrativas abreviadas

Com a pesquisa e reflexão sistemática sobre narrativa e orientação tenmporal, avançouse, a) na clarificação de sentidos atribuídos a conceitos operatórios ligados à ideia de consciência histórica, como 'narrativa abreviada', 'símbolos de identidade', identidade coletiva e, b) no estabelecimento de conexões entre conceitos de empatia histórica, identidades e interculturalidade. 
A reflexão epistemológica em torno da mensagem nuclear - ou meta narrativa - que atravessa a maioria das produções individuais sobre o país e o mundo, e que dá sinais das tendências mais marcantes de orientação identitária, conduziu também a um enfoque sobre outras manifestações de narrativa abreviada. Por exemplo, os símbolos de identidade de um país, de uma cultura ou da humanidade constituem-se também como uma narrativa abreviada. A partir desta ideia, no âmbito do Projeto Hicon desenvolveu-se um estudo empírico com alunos do $3^{\circ}$ ciclo do ensino básico $\left(7^{\circ}\right.$ a $9^{\circ}$ anos) que permitisse, dentro do quadro teórico referenciado, responder a questões sobre como os jovens representam simbolicamente a sua identificação com o país. Essas questões sobre a identificação simbólica envolviam uma tentativa de inferir, pelas escolhas e argumentos dos jovens participantes, tipos de consciência histórica aí sugeridos (tradicional, exemplar, crítica, ontogenética). Para este estudo focalizado em narrativas abreviadas que funcionam como símbolos representativos do país selecionou-se uma amostra participante de alunos de $9^{\circ}$ ano, de diversos contextos geográficos. Efetuou-se uma amostragem estratificada atendendo à localização da escola em três grandes regiões de Portugal Continental (Norte, Centro e Sul). E porque nesta pesquisa específica se pretendia alcançar um certo grau de representatividade da amostra considerou-se também como critério de amostragem atender ao sucesso na disciplina de História, por escola. O primeiro momento no processo de amostragem consistiu na identificação de 12 escolas, quatro em cada região, com médias de classificação mais e menos elevadas no exame de História do $12^{\circ}$ ano no ano anterior. Estes dados foram obtidos online, através da publicação de ranking de escolas dos Exames de Secundário. Desse conjunto, selecionaram-se seis escolas (duas por região), que obedeciam aos critérios pré-estabelecidos e que ofereciam algumas condições de acessibilidade à equipa de investigação para efeitos de recolha de dados. Das seis escolas contactadas para participar no estudo, três delas aceitaram de imediato - uma no Algarve, uma em Lisboa e uma no Minho. Numa segunda fase de amostragem, para perfazer a amostra participante seguindo os critérios pré-estabelecidos, selecionaram-se mais três escolas, uma no Algarve, uma em Lisboa e uma no Minho, que aceitaram participar graças a frequentes contactos pessoais. A amostra participante, constituída por alunos de seis turmas do $9^{\circ}$ ano, cada uma selecionada aleatoriamente por escola, perfazia cerca de 150 alunos no total. Verificou-se, após o contacto com as escolas, que a amostra apresentava características socioeconómicas e culturais muito diversificadas, abrangendo no Centro (Lisboa) e Sul (Algarve) alunos portugueses e de outras regiões do mundo (europeus do norte e do leste, africanos, brasileiros). Esta heterogeneidade cultural permitiria estudar melhor as questões identitárias, nomeadamente, ver a identidade nacional pelos olhares de "nós" e dos "outros" que interagem em Portugal. Mesmo com estes cuidados de amostragem, assumiu-se que a amostra participante poderia fornecer apenas alguns sinais sobre o pensamento dos jovens mas sem pretensões de generalização de resultados pois a amostra não oferecia garantias estatísticas de representatividade dos alunos de $9^{\circ}$ ano em Portugal Continental.

Em simultâneo com o processo de amostragem, construiu-se uma primeira versão do instrumento de recolha de dados, constituído por um questionário com itens de resposta aberta, e que foi sendo testado em turmas disponíveis do $3^{\circ}$ ciclo de escolaridade. $\mathrm{Na}$ sua forma final, o questionário apresentou questões de escolha múltipla e de resposta aberta, entre as quais:

1. Um item de escolha múltipla construído em torno de eventuais símbolos de identidade portuguesa, sendo uns mais convencionais, outros informais: a bandeira; o hino; o bacalhau; o cravo vermelho; as caravelas; a Língua; o fado; o vinho do Porto.

2. Um item de resposta aberta para justificação das rejeições de alguns dos símbolos. 
As questões de escolha múltipla 'jogavam' com símbolos identitários como narrativas abreviadas, inspiradas no estudo de Marília Gago sobre concepções de professores ${ }^{35}$, e cujos resultados tinham mostrado convergências com o estudo acerca das Atitude Sociais dos Portugueses, integrado no estudo europeu European Social Survey. ${ }^{36}$ Esperava-se, portanto, que esses elementos poderiam indiciar manifestações de identidade e orientação temporal.

Com base na média da frequência de escolhas por item, os resultados desta análise de dados (ainda parcial) sugeriram que os alunos valorizam, a Bandeira, a Língua e o Hino como os elementos mais representativos da sua identidade. De realçar que a Língua e o Hino foram, também, os elementos que não foram nenhuma vez excluídos. Algumas conclusões, muito provisórias e parcelares, apontam para uma identificação convencional (Hino, Língua, Bandeira) e uma rejeição de outros símbolos com os argumentos de que não são exclusivos de Portugal ou suficientemente abrangentes da ideia do país. Em termos de elementos que parecem não representar de forma marcante a sua identidade destacam-se o bacalhau, as caravelas e o cravo vermelho. Assim, quanto a justificações para a exclusão desses elementos que, neste caso, não representariam a identidade de cada um, os alunos consideram o Bacalhau como parte da tradição portuguesa, mas, como disse o André, de 16 anos, "O bacalhau é tradicional em Portugal mas não é um elemento representativo do país". Já no que se refere às caravelas e ao 25 de Abril, as exclusões devem-se ao facto de tais símbolos tenderem a ser considerados apenas representativos de um momento da História de Portugal:

As caravelas são de facto representativas do País mas não de momento, foi só na época dos Descobrimentos e não fomos os únicos a usá-las (Carlos, 16 anos).

Símbolo de uma revolução, é apenas uma parte da história do país (Ana, 15 anos).

Para a equipa investigadora, muitas dúvidas permaneceram quanto à interpretação das respostas dos alunos - o que aliás é frequente em resultados com base sobretudo numa análise quantitativa. O cruzamento das respostas com a nacionalidade dos jovens permitiria dar alguma resposta à questão do olhar 'do lado de dentro' por comparação com um olhar 'de fora'. Uma análise qualitativa aprofundada com entrevistas a uma parte (estratificada) da amostra poderá vir a clarificar o sentido das posições dos alunos e ver se, por exemplo, a rejeição de símbolos do quotidiano (alimentação e bebidas típicas) acontece por se considerarem que estes são talvez menos respeitáveis do que os tradicionais símbolos político culturais e/ou se eventuais escolhas que simbolizam momentos significativos da história nacional (caravela, cravo vermelho) poderiam marcar posturas menos convencionais (crítica e até ontogenética). Para já, percebe-se a existência de uma tendência de orientação temporal de índole tradicional e formalista face aos símbolos do país.

\section{Questões de interculturalidade nas narrativas de jovens}

A atitude de abertura à compreensão dos outros, enquanto sujeitos individuais ou identidades coletivas, está no âmago do pensamento histórico. Tal não implica que essa compreensão - empatia histórica - envolva concordância com decisões e ações desses outros; implica, sim, que se procurem as causas e consequências de certas ações e situações do passado consideradas significativas, para que se possam estabelecer relações entre passado, presente e

\footnotetext{
${ }^{35}$ Marília Gago, 2007 (ibid.).

${ }^{36}$ José Sobral e Jorge Vala, "Atitudes Sociais dos Portugueses (ISSP - International Social Survey Programme)" (Instituto de Ciências Sociais da Universidade de Lisboa, 2007).
} 
possibilidades de futuro, 'usáveis' numa abordagem de orientação temporal flexível, sempre sujeita a revisão. A incidência na interação dos sujeitos em sociedade (que no ofício do historiador se interliga com preocupações de empatia histórica, como aqui se argumenta), encontra-se no plano da vida prática relacionada com posturas face à diversidade de grupos e culturas que cada vez mais comunicam entre si. Contudo estas possíveis convergências entre noções de empatia histórica e de interculturalidade na vida em sociedade não se encontravam ainda clarificadas até finais da década de 1990, no âmbito da investigação em Educação histórica. Com efeito, o quadro conceptual da abordagem intercultural assenta em três conceitos fundacionais - diversidade, relação e universalidade - cuja problematização emana da reflexão contemporânea no campo de várias Ciências Sociais e não propriamente da História. No Projeto Hicon, para se iniciar a pesquisa sob esse enfoque partiu-se da hipótese de que poderia haver convergências entre o quadro da consciência histórica manifestada pela narrativa (entendida esta como comunicação algo coerente de ideias sobre o passado através do uso de qualquer tipo de linguagem) e o quadro da consciência intercultural. ${ }^{37} \mathrm{O}$ sentido humano na compreensão do passado, patente nos trabalhos de Rüsen dentro de um quadro de neo humanismo - que integra a noção de diálogo intercultural - tornou-se relevante para tal conceptualização. ${ }^{38}$ Assim, foram sobretudo os contributos de Rüsen que ajudaram a construir uma perspectiva mais clara sobre a interconexão entre a cultura histórica (que integra noções de empatia) e o diálogo intercultural (que implica reconhecimento da diversidade e da importância das relação culturais) em ordem à valorização multi-perspetivada da universalidade do ser humano. Considera-se, portanto, que todas estas noções concorrem para a construção de uma consciência histórica avançada e complexa numa visão de realismo crítico, afastada de relativismos culturais radicais.

As preocupações subjacentes às intenções de aprofundar a compreensão da consciência histórica e intercultural de jovens levou ao lançamento de um estudo piloto com alunos do $7^{\circ}$ ano da escolaridade básica. A amostra participante era constituída por 47 alunos de 12-13 anos (18 meninos e 29 meninas) de duas turmas numa escola pública situada no centro do país, com uma população escolar heterogénea no plano sociocultural. $\mathrm{O}$ instrumento de recolha de dados apresentava a seguinte proposta de narrativa a ser elaborada por cada aluno ${ }^{39}$ :

Há mais de 60.000 anos vários grupos de homens, mulheres e crianças saíram de Africa e povoaram os vários continentes - Europa, Ásia e Austrália; mais tarde, há cerca de 20.000 anos, partiram também para o continente americano.

Continua a História da Humanidade em linhas gerais, considerando alguns movimentos de povos e grupos de pessoas (incluindo para Portugal) até aos dias de hoje.

A tarefa foi aplicada numa aula de História pelos professores das respetivas turmas, e que acederam a colaborar neste estudo. As respostas dos alunos proporcionaram a construção e afinamento progressivo de categorias de análise, num processo de codificação aberta, axial e seletiva tal como a Grounded Theory advoga. ${ }^{40}$ Dentro desta problemática propôs-se, como hipótese aberta a contínuos reajustamentos, um modelo provisório de ideias dos jovens numa perspectiva de progressão conceptual em relação às movimentações e interações de povos: 1 . Movimentos centrados no presente, 2. Movimentos num tempo em contracção, 3. Movimentos em "friso cronológico", 4. Movimentos num tempo dinâmico.

\footnotetext{
${ }^{37}$ Júlia Castro, 2009 (ibid.).

${ }^{38}$ Jörn Rüsen, 2015 (ibid.).

${ }^{39}$ Esta proposta foi desenhada com os contributos diretos de Denis Shemilt e Peter Lee, investigadores britânicos pioneiros da investigação em educação histórica, no Seminário da Arrábida sobre "Consciência histórica - teoria e práticas (Sesimbra, 2008).

${ }_{40}$ Anselm Strauss e Juliet Corbin, 1991 (ibid.).
} 
Nas narrativas consideradas dentro da categoria "Movimentos centrados no presente", os alunos limitam-se a sinalizar migrações de povos na atualidade, integrando aí situações de migração (imigração e/ou emigração), omitindo referências ao passado:

Hoje em dia os povos vão para os países mais ricos, como a França e a Suíça. E como em Portugal há grandes dificuldades económicas, as pessoas emigram (José, 12 anos)

As pessoas continuam a vir para Portugal porque tem boa vegetação e um clima agradável. Elas vem para procurar uma vida melhor e também para visitarem Portugal e verem as suas lindas paisagens (Maria, 12 anos)

Na categoria de "Movimentos num tempo dinâmico", a mais elaborada, as narrativas abordam movimentações em vários tempos, de vários povos e com diversas motivações:

Fenícios, Gregos e Cartagineses vieram para a Península Ibérica para comerciar, e por isso estabeleceram colónias e empresas comerciais. Os Romanos ocuparam toda a região do Mediterrâneo, incluindo Portugal. Os povos Árabes conquistaram terras em África, Ásia e Europa. Mais tarde, os Portugueses foram descobrir e conquistar por via marítima. Descobriram os Açores e a Madeira e conquistaram Ceuta, Brasil, Índia e a costa africana. Os Espanhóis quiseram conquistar o nosso território mas não conseguiram. (Fátima, 12 anos)

Se as narrativas historicamente menos elaboradas assentam numa genérica luta pela sobrevivência e por uma vida melhor como a principal motivação a dar significado às movimentações de povos no passado e no presente, as mais elaboradas apresentam também razões historicamente situadas para essas movimentações (como comércio e conquistas, no exemplo acima). Contudo, no global são raras as narrativas em que as movimentações de povos no passado mostram sinais abertos de interação cultural. Guerra ou comércio implicam interações violentas ou pacíficas entre povos, mas nestas indicações quase só são consideradas as motivações dos povos que se movimentam. Não há visibilidade de 'outros' povos ou grupos com quem eles guerreiam ou comerciam, nem surgem referências a contributos positivos e negativos desses contactos. Contudo, pontualmente emerge uma atenção aos grupos ou povos que sofrem com o contacto adverso com o 'outro':

Os Hebreus foram para o Egito onde foram escravizados e depois foram para a Palestina ... (Joana, 12 anos)

Os Africanos deixaram a África para vir para Portugal, mas a maioria veio como escravos, emigrar para eles poderia significar escravidão. (Artur, 12 anos)

\section{Considerações finais: desafios para a Didática da História}

Esta conceptualização, que aqui se considera mais dinâmica e atualizada da História enquanto resposta a necessidades de orientação temporal, permite iluminar a compreensão da importância da História para a formação dos alunos em termos de aprofundamento dos horizontes de expectativa individuais e coletivos. Tal obriga a uma interligação conceptual dos vários segmentos temporais - passado, presente e futuro - e que se traduz na exigência de desenvolver, em aula, o pensamento histórico numa perspectiva explicativa. Como dizia um jovem britânico numa entrevista, "vai-se ao passado em direção ao futuro". ${ }^{41}$ Com efeito, quando em História se procura discernir consequências de um passado não estarão presentes as categorias conceptuais dos segmentos presente e futuro, embora sendo esses dois segmentos já parte do nosso passado?

\footnotetext{
${ }^{41}$ Tradução livre da expressão "walking backwards into tomorrow”, utilizada no título do artigo de Peter Lee, 2002 (ibid.).
} 
Por outro lado, a preocupação de educar os jovens historicamente coloca em foco a importância do aluno como sujeito que, pelo seu agir esclarecido pela cultura histórica, pode (e deve) procurar resolver carências da sua orientação temporal, tal como a pesquisa de $\mathrm{M}$. Auxiliadora Schmidt e sua equipa tem amplamente mostrado. ${ }^{4243} \mathrm{~A}$ detecção destas carências e a sua progressiva tomada de consciência por parte dos alunos constitui uma proposta vital para o empoderamento dos jovens cidadãos.

Acrescente-se ainda que, de acordo com a proposta de desenvolvimento da consciência histórica, a ênfase na ação dos sujeitos não significa um reforço de individualismos perigosos. Significa, pelo contrário, aprender a praticar a empatia histórica traduzida no diálogo intelectual com os diversos "outros", sejam seres humanos do passado, do presente e, também, do futuro (na medida em que podemos perspectivar consequências das ações do presente para os sujeitos vindouros). Os jovens estarão assim mais preparados para procurar entender o estranho e, por isso, mais aptos a selecionar opções para si próprio, numa perspectiva de humanismo intercultural.

Toda esta discussão tem ligação com as preocupações em torno do desenvolvimento da consciência histórica dos principais agentes educativos (alunos e professores), como Jörn Rüsen advoga ${ }^{44}$. Para avançar nesta compreensão, a investigação em Educação histórica continua apostada em diagnosticar aprendizagens e apresentar algumas pistas concretas de ensino que possam ser úteis na prática da aula de História. Em Portugal, visa-se agora, a) atualizar e aprofundar resultados obtidos no Projeto Hicon quanto à estrutura e substância das narrativas de jovens portugueses bem como quanto às mensagens nucleares e outras formas de narrativa abreviada aí implícitas; b) atender a contextos culturais cada vez mais diversificados, procurando-se recolher dados não só em turmas com alunos imigrantes em Portugal como também em escolas de outros países lusófonos; c) efetuar estudos qualitativos comparativos sobre narrativas de jovens de diferentes países - por exemplo, de alunos espanhóis e portugueses, em curso; d) analisar aulas com um recorte próximo da 'aula oficina' para perceber como e até que ponto os professores e alunos lidam com ideias de orientação temporal em situações de aula.

Todo este programa aspira a estimular a inovação no pensamento e ação de ensinar e aprender que seja consentânea com uma perspectiva do aluno e do professor enquanto sujeitos que interagem na busca de dar sentido humano ao que aprendem em História, com significado para a sua própria orientação no tempo.

\footnotetext{
42 Maria Auxiliadora Schmidt, "Hipóteses ontogenéticas relativas à consciência moral: possibilidades da consciência histórica de jovens brasileiros", Educar em Revista, Dossiê: História, epistemologia e ensino: desafios de um diálogo em tempos de incertezas (2011).

${ }^{43}$ Maria Auxiliadora Schmidt e Lucas Pydd Nechi, 2016 (ibid.).

${ }^{44}$ Ver "Jörn Rüsen e o ensino de História”, 2010 (ibid.).
} 